\title{
Rat Cholangiocytes Absorb Bile Acids at Their Apical Domain via the lleal Sodium-dependent Bile Acid Transporter
}

\author{
Konstantinos N. Lazaridis, ${ }^{\star}$ Linh Pham, ${ }^{\star}$ Pam Tietz, ${ }^{\star}$ Raul A. Marinelli, ${ }^{\star}$ Piet C. deGroen, ${ }^{\star}$ Susan Levine, ${ }^{\star}$ Paul A. Dawson, ${ }^{\S}$ \\ and Nicholas F. LaRusso* \\ * Center for Basic Research in Digestive Diseases, Division of Gastroenterology and Internal Medicine, and ${ }^{\ddagger}$ Department of Biochemistry \\ and Molecular Biology, Mayo Medical School, Rochester, Minnesota 55905; and ${ }^{\S}$ Department of Internal Medicine-Gastroenterology, \\ Bowman Gray School of Medicine, Wake Forest University, Winston-Salem, North Carolina 27157
}

\begin{abstract}
Although bile acid transport by bile duct epithelial cells, or cholangiocytes, has been postulated, the details of this process remain unclear. Thus, we performed transport studies with $\left[{ }^{3} \mathrm{H}\right]$ taurocholate in confluent polarized monolayers of normal rat cholangiocytes (NRC). We observed unidirectional (i.e., apical to basolateral) $\mathrm{Na}^{+}$-dependent transcellular transport of $\left[{ }^{3} \mathrm{H}\right]$ taurocholate. Kinetic studies in purified vesicles derived from the apical domain of NRC disclosed saturable $\mathrm{Na}^{+}$-dependent uptake of $\left[{ }^{3} \mathrm{H}\right]$ taurocholate, with apparent $K_{\mathrm{m}}$ and $V_{\max }$ values of $209 \pm 45 \mu \mathrm{M}$ and $1.23 \pm 0.14$ nmol/mg/10 s, respectively. Reverse transcriptase PCR (RTPCR) using degenerate primers for both the rat liver $\mathrm{Na}^{+}$dependent taurocholate-cotransporting polypeptide and rat ileal apical $\mathrm{Na}^{+}$-dependent bile acid transporter, designated Ntcp and ASBT, respectively, revealed a 206-bp product in NRC whose sequence was identical to the ASBT. Northern blot analysis demonstrated that the size of the ASBT transcript was identical in NRC, freshly isolated cholangiocytes, and terminal ileum. In situ RT-PCR on normal rat liver showed that the message for ASBT was present only in cholangiocytes. Immunoblots using a well-characterized antibody for the ASBT demonstrated a $48-\mathrm{kD}$ protein present only in apical membranes. Indirect immunohistochemistry revealed apical localization of ASBT in cholangiocytes in normal rat liver. The data provide direct evidence that conjugated bile acids are taken up at the apical domain of cholangiocytes via the ASBT, and are consistent with the notion that cholangiocyte physiology may be directly influenced by bile acids. (J. Clin. Invest. 1997. 100:2714-2721.) Key words: biliary epithelia - taurocholate - transport • liver • plasma membrane vesicles
\end{abstract}

\section{Introduction}

The enterohepatic circulation $(\mathrm{EHC})^{1}$ of bile acids constitutes an important physiologic component of the digestive system in

Preliminary portions of this work were presented at the 47th meeting of the American Association for the Study of Liver Diseases, and have been published in abstract form (1996. Hepatology. 94:897a).

Address correspondence to Nicholas F. LaRusso, Center for Basic Research in Digestive Diseases, Mayo Clinic, 200 First Street, SW, Rochester, MN 55905. Phone: 507-284-1006; FAX: 507-284-0762.

Received for publication 26 March 1997 and accepted in revised form 10 October 1997.

The Journal of Clinical Investigation

Volume 100, Number 11, December 1997, 2714-2721

http://www.jci.org all mammals (1). To achieve vectorial transport of bile acids against concentration gradients (2), this pathway requires the coordinated activities of epithelial cells in both the distal small intestine and liver that express bile acid transporters on their apical and basolateral membrane domains (2). Recently, an apical $\mathrm{Na}^{+}$-dependent bile acid transporter, designated ASBT, was cloned from hamster, human, and rat (3-5) and shown to be located at the apical domain of epithelial cells lining the ileum. In addition, two bile acid transporters have been cloned from liver (6). The first, the liver $\mathrm{Na}^{+}$-dependent taurocholatecotransporting polypeptide, designated Ntcp, is localized selectively on the basolateral (sinusoidal) domain of hepatocytes ( 7 , 8 ), and is the protein principally responsible for bile acid transport from portal blood into the hepatocyte (6). The second, the rat liver organic anion transporting polypeptide, is also located at the basolateral plasma membrane of hepatocytes, but is $\mathrm{Na}^{+}$-independent (9). Although biliary epithelia, or cholangiocytes, the cells that line the bile ducts inside the liver, are anatomical components of the EHC, it is unclear to what extent they participate functionally in bile acid transport. Indeed, no bile acid transporters have yet been identified definitively on biliary epithelia.

The cholehepatic shunt hypothesis (10) provides a possible scenario by which cholangiocytes may participate in the EHC of bile acids. This pathway was proposed by Hofmann and colleagues to explain the hypercholeresis induced by selected unconjugated bile acids $(10,11)$. Based in part on the known physicochemical properties of bile acids and on physiologic observations of bile acid transport made in the intestine, the hypothesis proposes that an unconjugated bile acid anion is protonated in the canaliculus, absorbed passively into the cholangiocyte, and then secreted at the basolateral cholangiocyte domain (10). From there, the bile acid molecule enters the periductular capillary plexus and proceeds to the sinusoids to be reabsorbed by the hepatocyte where it can be resecreted into bile, promoting additional canalicular bile secretion (10). While provocative, evidence for this pathway is indirect, and the molecular mechanisms involved remain unknown. Moreover, since virtually all bile acids in mammalian bile are conjugated to taurine or glycine (1), the physiologic relevance of this pathway in the absence of exogenously administrated bile acids that resist conjugation remains obscure. Thus, the aim of the work described here was to begin to investigate directly the

1. Abbreviations used in this paper: ASBT, rat ileal apical $\mathrm{Na}^{+}$-dependent bile acid transporter; BBMV, brush border membrane vesicles; CK, cytokeratin; EHC, enterohepatic circulation; GAPDH, glyceraldehyde-3-phosphate dehydrogenase; NRC, normal rat cholangiocytes; Ntcp, rat liver $\mathrm{Na}^{+}$-dependent taurocholate-cotransporting polypeptide; RT-PCR, reverse transcriptase PCR; TEER, transepithelial electrical resistance. 
transport capacity of cholangiocytes for bile acids using novel experimental models developed in our laboratory (12-14, and see reference 17) as an initial effort in exploring a potential role for bile acids in cholangiocyte physiology.

\section{Methods}

Animals. Male Fisher 344 rats (225-250 g) purchased from Harlan Sprague Dawley Inc. (Indianapolis, IN) were maintained in a temperature-controlled environment $\left(22^{\circ} \mathrm{C}\right)$, had free access to water, and were fed ad libitum.

Materials. $\left[{ }^{3} \mathrm{H}\right]$ Taurocholate (specific activity $3.47 \mathrm{Ci} / \mathrm{mmol}$ ) of $>95 \%$ purity by thin-layer chromatography was purchased from DuPont-NEN (Boston, MA), and $\left[\alpha^{-32} \mathrm{P}\right] \mathrm{UTP}$ (specific activity $800 \mathrm{Ci} /$ $\mathrm{mmol}$ ) of $>95 \%$ purity by thin-layer chromatography was obtained from Amersham Corp. (Arlington Heights, IL). All other reagents were purchased from Sigma Chemical Co. (St. Louis, MO) unless otherwise indicated.

Transport studies in cultured rat cholangiocytes. Polarized normal rat cholangiocytes (NRC) in long-term culture (passages 50-61) were used (14). For transport studies, NRC were grown on rat tail collagen-coated $0.2-\mu \mathrm{m}$ ANOPORE filters in tissue culture inserts (Nunc, Inc., Roskilde, Denmark) containing serum-free cholangiocyte growth medium (14) and incubated at $37^{\circ} \mathrm{C}$ in the presence of $95 \% \mathrm{O}_{2}$ and $5 \% \mathrm{CO}_{2}$. Under these conditions, monolayers became confluent in $72 \mathrm{~h}$, and transepithelial electrical resistance (TEER) reached $1,000 \Omega \cdot \mathrm{cm}^{2}$ after $7 \mathrm{~d}$ (14). In these experiments, we used the following incubation buffers: (a) modified HBSS (15), $\mathrm{pH} 7.4$, containing (mM) $0.44 \mathrm{KH}_{2} \mathrm{PO}_{4}, 0.34 \mathrm{~K}_{2} \mathrm{HPO}_{4}, 4.17 \mathrm{KHCO}_{3}, 1.26 \mathrm{CaCl}_{2}$, $0.49 \mathrm{MgCl}_{2} \cdot 6 \mathrm{H}_{2} \mathrm{O}, 0.41 \mathrm{MgSO}_{4} \cdot 7 \mathrm{H}_{2} \mathrm{O}, 136.9 \mathrm{NaCl}, 5.55$ glucose, and 10.0 Mops; $(b) \mathrm{Na}^{+}$-free modified HBSS containing the same reagents and concentrations as the modified HBSS buffer, with the exception that $\mathrm{NaCl}$ was replaced by tetra-methyl-ammonium chloride $\left[\left(\mathrm{CH}_{3}\right)_{4} \mathrm{~N}^{+} \mathrm{Cl}^{-}\right]$.

Transport studies were done in triplicate on confluent polarized NRC monolayers that retained TEER $>1,000 \Omega \cdot \mathrm{cm}^{2}$. TEER was monitored, and remained high before, during, and after the transport studies. Cholangiocyte growth medium was removed from both the apical and basolateral chambers, and the polarized NRC monolayers were washed twice with incubation buffer. Subsequently, the culture inserts were preincubated with incubation buffer for $30 \mathrm{~min}$ at $37^{\circ} \mathrm{C}$ in the presence of $95 \% \mathrm{O}_{2}$ and $5 \% \mathrm{CO}_{2}$. Then, a mixture of $\left[{ }^{3} \mathrm{H}\right]$ taurocholate to unlabeled taurocholate (1:150) was added to the apical or basolateral chambers of the culture inserts, exposing the apical or basolateral domain of NRC, to a final concentration of $200 \mu \mathrm{M}$ taurocholate. Cultures were incubated at $37^{\circ} \mathrm{C}$ for $1 \mathrm{~h}$; the apical and basolateral media were then collected. Apical and basolateral media were then mixed separately with Opti-Fluor cocktail (Packard, Meriden, CT), and liquid-scintillation counting was performed. The nanomoles of total taurocholate transported transcellularly in each direction were calculated, and the results were expressed as nanomoles of taurocholate per square centimeter of filter per hour.

Transport studies in apical vesicles derived from NRC. Uptake experiments were performed in triplicate using apical cholangiocyte plasma membrane vesicles derived from NRC in culture (passages 50-61) and the rapid filtration technique (16). This vesicle preparation has been characterized extensively by us (17) and is well-suited for transport studies, since the vesicles are predominately sealed $(>90 \%)$ and right side out (75\%) (17). Vesicles (40 $\mu \mathrm{g}$ of total protein per experiment) were resuspended at a final concentration of $2 \mathrm{mg} / \mathrm{ml}$ in resuspension buffer containing (mM) 300 sucrose, 10 Hepes ( $\mathrm{pH} 7.5)$, $10 \mathrm{MgSO}_{4}$, and $0.2 \mathrm{CaCl}_{2}$. Initially, uptake was measured for various times of incubation ( $5 \mathrm{~s}-1 \mathrm{~min})$ of vesicles with the substrate (i.e., taurocholate). For kinetic analysis, $80 \mu \mathrm{l}$ of incubation buffer containing $(\mathrm{mM}) 125 \mathrm{NaCl}$ or choline chloride, 50 sucrose, 10 Hepes (pH 7.5), 10 $\mathrm{MgSO}_{4}, 0.2 \mathrm{CaCl}_{2}$, and a mixture of $\left[{ }^{3} \mathrm{H}\right]$ taurocholate and increasing amounts of unlabeled taurocholate to yield a range of final taurocho- late concentrations $(10-250 \mu \mathrm{M})$, was added to the vesicles. Uptake was initiated by vortexing the mixture. After incubation for $10 \mathrm{~s}$ at room temperature, taurocholate uptake was terminated by adding $3.5 \mathrm{ml}$ ice-cold stop solution containing $(\mathrm{mM}) 100 \mathrm{NaCl}$ or choline chloride, 100 sucrose, 10 Hepes ( $\mathrm{pH} 7.5$ ), $10 \mathrm{MgSO}_{4}$, and $0.2 \mathrm{CaCl}_{2}$. The incubation mixtures were then filtered immediately through a $0.45-\mu \mathrm{m}$ HAWP filter (Millipore Corp., Bedford, MA) presoaked in stop solution and prefiltered with $1 \mathrm{mM}$ taurocholate using a rapid-sampling filtration system (Millipore Corp.). The filters were then washed two times with $3.5 \mathrm{ml}$ ice-cold stop solution, mixed, and dissolved in $10 \mathrm{ml}$ Ready Solv HP cocktail (Beckman Instruments Inc., Fullerton, CA), and liquid-scintillation counting was performed. Nonspecific binding of $\left[{ }^{3} \mathrm{H}\right]$ taurocholate to the filters was determined by adding the icecold stop solution before the addition of incubation buffer, and the counts were subtracted from each sample. The $\mathrm{Na}^{+}$-dependent uptake was defined as uptake in the presence of $\mathrm{Na}^{+}$minus uptake in the presence of choline. The taurocholate uptake was calculated and expressed as picomoles of taurocholate per milligram of membrane vesicle protein per 10 seconds. Using a kinetic program (Enzfitter, version 1.05; Elsevier-Biosoft, Cambridge, UK), the apparent $K_{\mathrm{m}}$ and $V_{\max }$ values of this transport process were calculated.

Organs and freshly isolated/cultured cells. Organs (i.e., terminal ileum, heart) were removed from normal rats, rinsed twice in ice-cold buffer A (18), snap-frozen, and stored at $-70^{\circ} \mathrm{C}$ until used for RNA isolation. Freshly isolated, highly purified hepatocytes and cholangiocytes were prepared from normal rat liver as described (18). NRC were separated from collagen using high-purity collagenase for 45 min at $37^{\circ} \mathrm{C}$, washed with Hepes-buffered saline three times, and pelleted. The harvested cells were used for preparation of apical and basolateral cholangiocyte plasma membrane vesicles and for RNA extraction.

Reverse transcriptase PCR (RT-PCR). Total cellular RNA was extracted from freshly isolated, highly purified hepatocytes and from NRC by the single-step method of Chomczynsky and Sacchi (19). Total cellular RNA was further purified with cesium chloride ultracentrifugation, and first-strand cDNA was synthesized using the SuperScript preamplification system (GIBCO BRL, Gaithersburg, MD). Degenerate oligonucleotide primers were synthesized based on published sequences for the rat Ntcp (7) and rat ASBT (5), specifically, 5'-CAGTTTGG(C/A)ATCATGCC(C/T)CTC-3' (forward) and $5^{\prime}-(\mathrm{A} / \mathrm{G}) \mathrm{AG}(\mathrm{G} / \mathrm{T}) \mathrm{GGCATCAT}(\mathrm{G} / \mathrm{T}) \mathrm{CC}(\mathrm{A} / \mathrm{C}) \mathrm{A}(\mathrm{A} / \mathrm{G}) \mathrm{GGC}-3^{\prime}$ (reverse). PCR was performed using the GeneAmp PCR reagent kit and Amplitaq DNA polymerase (Perkin-Elmer Corp., Norwalk, CT) according to the vendor's instructions. The PCR products from each template (i.e., hepatocytes, NRC) were cloned in the pCR II vector (Invitrogen Corp., San Diego, CA), designated pCR II-Ntcp and pCR II-ASBT, respectively, and sequenced (Mayo Molecular Core Facility, Rochester, MN). Each sequence was compared with those published for the rat Ntcp (7) and ASBT (5).

Ribonuclease Protection Assays (RPAs). The assays were performed using the RPA II kit (Ambion Inc., Austin, TX) and $10 \mu \mathrm{g}$ of total RNA extracted from different rat tissues and from freshly isolated and cultured cells as described above. Briefly, an antisense ${ }^{32} \mathrm{P}$-labeled riboprobe was transcribed from the pCR II-ASBT and pCR II-Ntcp, respectively, using $\left[\alpha^{-32} \mathrm{P}\right] \mathrm{UTP}$ and $\mathrm{T}_{7}$ RNA polymerase. The primary RNA transcript from each clone was purified by excision from a $5 \%$ acrylamide $/ 8 \mathrm{M}$ urea denaturing gel and subsequently eluted into a solution of $0.5 \mathrm{M}$ ammonium acetate, $1 \mathrm{mM}$ EDTA, and $0.1 \%$ SDS at $37^{\circ} \mathrm{C}$. Each antisense riboprobe was hybridized with total RNA from the different tissues or isolated cells at $45^{\circ} \mathrm{C}$ for $12 \mathrm{~h}$. Unhybridized RNA was digested by a mixture of RNase $\mathrm{A} / \mathrm{T}_{1}$ (150-200 U/ml). The protected hybrid (206 bp) was resolved in a 5\% acrylamide $/ 8 \mathrm{M}$ urea gel and detected after exposure to $\mathrm{x}$-ray film (Eastman Kodak Co., Rochester, NY) for $4 \mathrm{~h}$ at $-70^{\circ} \mathrm{C}$. Glyceraldehyde-3-phosphate dehydrogenase (GAPDH) (Ambion Inc.) was used as a housekeeping gene.

Northern blot analysis. Total cellular RNA was extracted from terminal ileum, freshly purified cholangiocytes and hepatocytes (18), 
and NRC as described above. Poly(A) ${ }^{+}$RNA was isolated using an oligo (dT) cellulose column (Stratagene Inc., La Jolla, CA). Poly(A) ${ }^{+}$ RNA samples $(2 \mu \mathrm{g})$ were electrophoresed through a $6 \%$ formaldehyde/denaturing $1 \%$ agarose gel. The RNA was transferred to a nylon membrane (Hybond; Amersham Corp.), bound to the filter by ultraviolet cross-linkage, and hybridized at $70^{\circ} \mathrm{C}$ with the same ${ }^{32} \mathrm{P}$-labeled cRNA ASBT probe as in the RPA. After hybridization, the filters were washed under high-stringency conditions using $2-0.1 \times$ SSC containing $0.1 \%$ SDS at $70^{\circ} \mathrm{C}$, and exposed to $\mathrm{x}$-ray film (Eastman Kodak Co.) using intensifier screens at $-70^{\circ} \mathrm{C}$ for $7 \mathrm{~h}$.

In situ RT-PCR. Frozen serial sections $(4 \mu \mathrm{m})$ from normal rat liver were prepared and applied on silanized glass slides as described $(20,21)$. Specific oligonucleotide primers for rat cytokeratin (CK) 19 , a protein expressed in liver only in cholangiocytes, $5^{\prime}$-GCACTGTGGCAGAGATAGAGG-3' (forward) and 5'-ACAAGTCAAGGGAAGGGCTGG-3' (reverse), and rat ASBT, 5'-ACAACTCTCCTTTAGCCC-3' (forward) and 5'-CTTTCTTCTTTTGCCTCC-3' (reverse) were constructed based on the published sequences (5). In situ RT-PCR was performed on the serial sections of normal rat liver using the above primers for CK-19 and ASBT, and $2.5 \mu \mathrm{M}$ digoxigenin-11-dUTP (Boehringer Mannheim Biochemicals, Indianapolis, IN) as described previously (20).

Preparation of plasma membranes and immunoblotting. Ileal brush border membrane vesicles (BBMV) were prepared as described (22). Crude, apical, and basolateral plasma membranes were prepared from NRC as described (17). Hepatocyte crude plasma membranes were isolated as described (16). Ileal brush border membranes, crude hepatocyte plasma membranes, as well as crude, apical, and basolateral plasma membranes from NRC were loaded and run on a $10 \%$ polyacrylamide gel; subsequently, the proteins were transferred to nitrocellulose (23) (Micron Separations, Inc., Westboro, MA). Immunoblots were performed using a well-characterized specific polyclonal rabbit anti-ASBT carboxy-terminal antipeptide antibody as described (5). Immunodetection was carried out using a chemiluminescence detection system (ECL; Amersham Corp.). The specificity of the anti-ASBT antibody was evaluated by stripping and reprobing the Western blot after preabsorption $\left(37^{\circ} \mathrm{C}\right.$ for $\left.1 \mathrm{~h}\right)$ of the antibody $(3$ $\mathrm{mg} / \mathrm{ml})$ with the 14 -amino acid peptide $(2 \mathrm{mg} / \mathrm{ml})$ with which the antiASBT was generated.

Immunohistochemistry. Immunohistochemical localization of the ASBT gene product was performed as described (24). Briefly, frozen sections $(10 \mu \mathrm{m})$ of normal rat terminal ileum or liver were cut, fixed with $100 \%$ acetone for $10 \mathrm{~min}$, and air dried. The sections were blocked with $5 \%$ goat serum and incubated with a 1:50 dilution of the same primary antibody as in Western blot analysis. Immunodetection was carried out using a goat anti-rabbit IgG biotinylated antibody (1:200 dilution) and the Vectastain ABC Kit (Vector Laboratories, Inc., Burlingame, CA) from the same vendor.

Densitometry. Densitometric analysis was performed using an imaging densitometer (model SG-700; Bio-Rad Laboratories, Hercules, CA).

Statistics. All values were expressed as mean \pm SEM. Statistical differences between means were calculated by the Student's $t$ test, and results were considered statistically different at $P<0.05$.

\section{Results}

Transport studies. Initially, we studied the transcellular transport of taurocholate in confluent polarized NRC monolayers. Fig. 1 shows the transcellular transport of taurocholate when the apical and basolateral domains of NRC were exposed to $200 \mu \mathrm{M}$ of taurocholate in the presence or absence of $\mathrm{Na}^{+}$and cells were harvested at $1 \mathrm{~h}$. As can be seen, the transcellular transport of taurocholate in $\mathrm{NRC}$ is $\mathrm{Na}^{+}$dependent at the apical but not basolateral domain (Fig. 1). Specifically, the transcellular transport of taurocholate (apical to basolateral) was

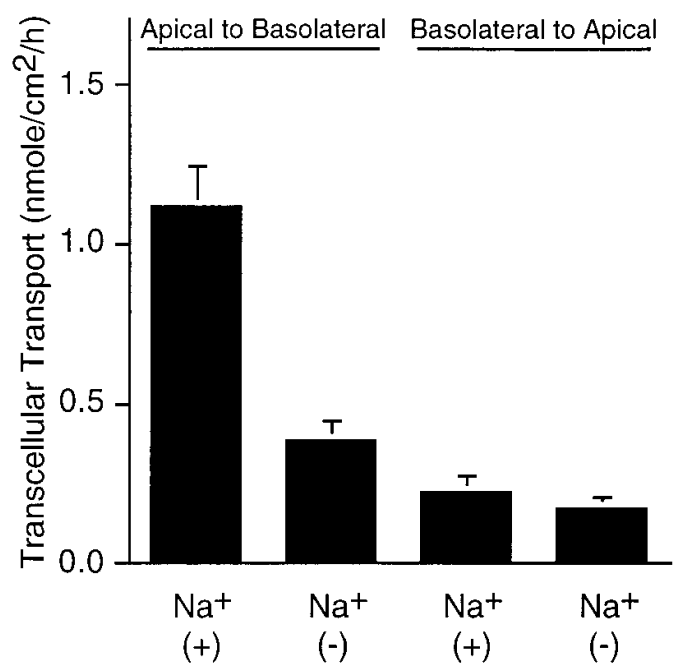

Figure 1. Transcellular transport of taurocholate by NRC. The apical and basolateral domains of NRC were exposed to $200 \mu \mathrm{M}$ of taurocholate (a mixture of $\left[{ }^{3} \mathrm{H}\right]$ taurocholate and unlabeled taurocholate) in the presence and absence of $\mathrm{Na}^{+}$at $37^{\circ} \mathrm{C}$. After $1 \mathrm{~h}$, the apical and basolateral media were collected, and $\left[{ }^{3} \mathrm{H}\right]$ taurocholate was measured to determine the total amount of taurocholate that was transcellularly transported. Results are expressed as mean $\pm \operatorname{SEM}(n=3)$.

decreased by $\sim 70 \%$ in the absence of $\mathrm{Na}^{+}(P<0.01$ compared with transcellular transport in the presence of $\left.\mathrm{Na}^{+}\right)$. In contrast, basolateral to apical transcellular taurocholate transport was minimal and $\mathrm{Na}^{+}$independent (Fig. 1). The concentration of $200 \mu \mathrm{M}$ of taurocholate was chosen for these studies since pilot experiments revealed that this concentration was saturating for uptake by NRC monolayers (data not shown).

To confirm and extend this initial observation and to provide precise kinetic parameters, we studied taurocholate uptake by cholangiocyte apical membrane vesicles derived from NRC. First, we examined the uptake of taurocholate by cholangiocyte apical membrane vesicles over time. Fig. $2 A$ shows that the $\mathrm{Na}^{+}$-dependent uptake of taurocholate by cholangiocyte apical vesicles was linear for the first $15 \mathrm{~s}$. To study the kinetic parameters of this transport process, we performed uptake experiments of taurocholate in cholangiocyte apical membrane vesicles derived from NRC in the presence and absence of $\mathrm{Na}^{+}$ at initial rates $(10 \mathrm{~s})$. As can be seen (Fig. $2 \mathrm{~B}$ ), in the presence of $\mathrm{Na}^{+}$, the uptake process displays Michaelis-Menten kinetic characteristics with saturation at $\sim 200 \mu \mathrm{M}$. As in the studies with NRC monolayers, taurocholate uptake was $\mathrm{Na}^{+}$dependent (Fig. $2 \mathrm{~B}$ ). The apparent $K_{\mathrm{m}}$ and $V_{\max }$ for taurocholate uptake by apical vesicles estimated from the transport studies were $209 \pm 45 \mu \mathrm{M}$ and $1.23 \pm 0.14 \mathrm{nmol} / \mathrm{mg} / 10 \mathrm{~s}$, respectively.

Molecular studies. RT-PCR was performed using degenerate primers for Ntcp and ASBT and RNA extracted from highly purified rat hepatocytes and NRC. Single PCR products of 206 bp were amplified from total RNA of each cell type (Fig. $3 A$ ). Subsequently, each PCR product was cloned and sequenced. As expected, the product amplified from the RNA of isolated hepatocytes was identical to the corresponding portion of Ntcp (7). In contrast, the product amplified from the RNA of NRC was identical to a putative transmembrane portion of the rat ASBT (nucleotides 5' $338 \rightarrow 5443^{\prime}$ ) (5). An 
A

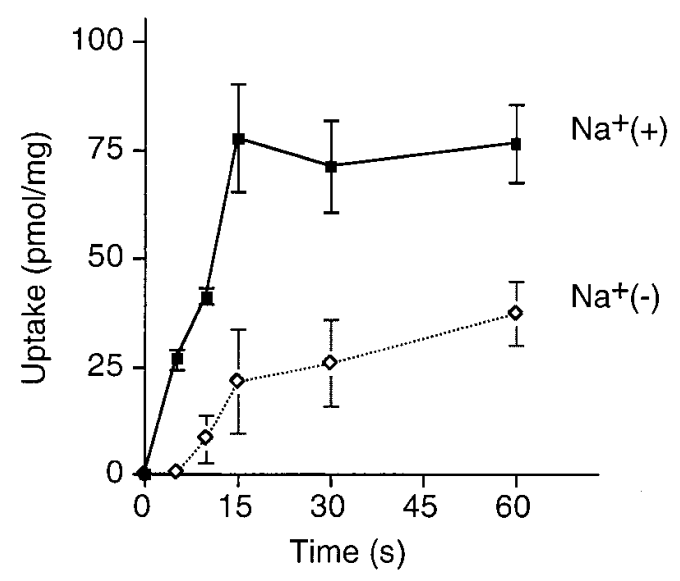

B

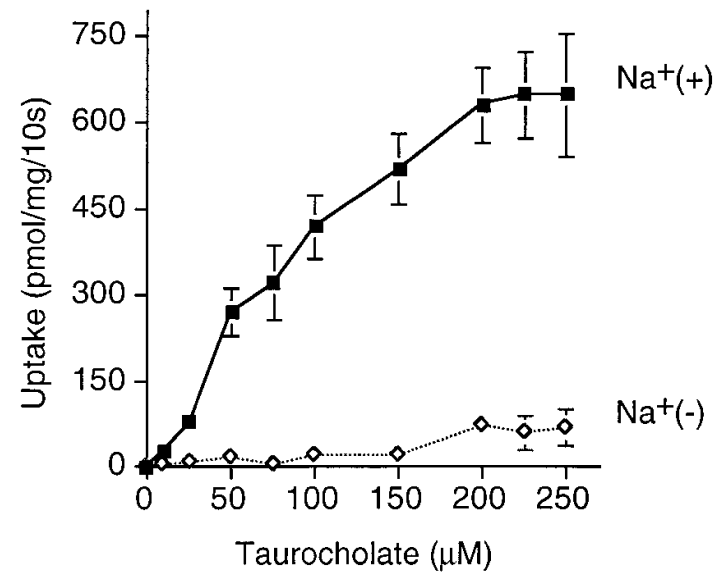

Figure 2. (A) Taurocholate uptake by apical vesicles derived from NRC over time. Cholangiocyte apical membrane vesicles from NRC were incubated with incubation buffer containing $10 \mu \mathrm{M}\left[{ }^{3} \mathrm{H}\right]$ taurocholate at room temperature in the presence and absence of $\mathrm{Na}^{+}$. The incubations were terminated at various times $(5 \mathrm{~s}-1 \mathrm{~min})$. Results are expressed as mean $\pm \operatorname{SEM}(n=3)$. (B) Taurocholate uptake by apical vesicles derived from NRC in the presence or absence of $\mathrm{Na}^{+}$. Cholangiocyte apical membrane vesicles from NRC were incubated with incubation buffer containing the indicated concentration of $\left[{ }^{3} \mathrm{H}\right]$ taurocholate $(10-250 \mu \mathrm{M})$ at room temperature in the presence or absence of $\mathrm{Na}^{+}$. The incubation was terminated after $10 \mathrm{~s}$, and the mixture was filtered immediately using the rapid filtration technique. $\left[{ }^{3} \mathrm{H}\right]$ Taurocholate was measured to determine the total amount of taurocholate uptake. Results are expressed as mean $\pm \operatorname{SEM}(n=3)$.

overlapping but longer RT-PCR product of $576 \mathrm{bp}$ amplified from RNA of NRC (primers and data not shown) was also $100 \%$ homologous to ASBT (nucleotides 5' $338 \rightarrow 9143^{\prime}$ ) (5).

To verify and extend these observations, specific cRNA probes were generated for both the ASBT and Ntcp, and RPAs were performed using total RNA isolated from different cells and tissues. As shown in Fig. 3 B, the message for ASBT was present in ileum and freshly isolated cholangiocytes but not in heart or freshly isolated hepatocytes. As expected, the message for Ntcp was present in isolated hepatocytes but absent in ileum, heart, and cholangiocytes (Fig. $3 \mathrm{~B}$ ). The mes- sage for GAPDH, a housekeeping gene, was expressed in all samples (Fig. 3 B). Furthermore, Northern blot analysis was performed to determine if the full-length transcript of ASBT was present in cholangiocytes. Fig. 4 shows that an identical size transcript $(5.0 \mathrm{~kb})$ was detected in terminal ileum (5) (positive control), NRC, and freshly isolated cholangiocytes. This message was absent in hepatocytes (Fig. 4). Based on densitometric analysis from our Northern blot data, we concluded that the message of ASBT in NRC was $\sim 2.5$-fold less compared with freshly isolated cholangiocytes. This finding is not uncommon in primary cell cultures (i.e., Ntcp in primary culture) (25).

To determine if cholangiocytes express the message for ASBT in vivo, in situ RT-PCR was performed on normal rat liver. Fig. 5 shows results of in situ RT-PCR carried out on serial sections of normal rat liver using specific primers for CK-19, a well-characterized marker of biliary epithelia, and for ASBT. As can be seen, cholangiocytes are the only cells in the liver that stain positively with each probe.

Biochemical studies. To generate additional evidence that ASBT is expressed in cultured cholangiocytes and to determine its subcellular location, we performed immunoblots with a specific antibody to ASBT using protein extracted from vesicles derived from either the apical or basolateral domain of NRC. Fig. $6 \mathrm{~A}$ demonstrates that a $48-\mathrm{kD}$ protein correspond-

A
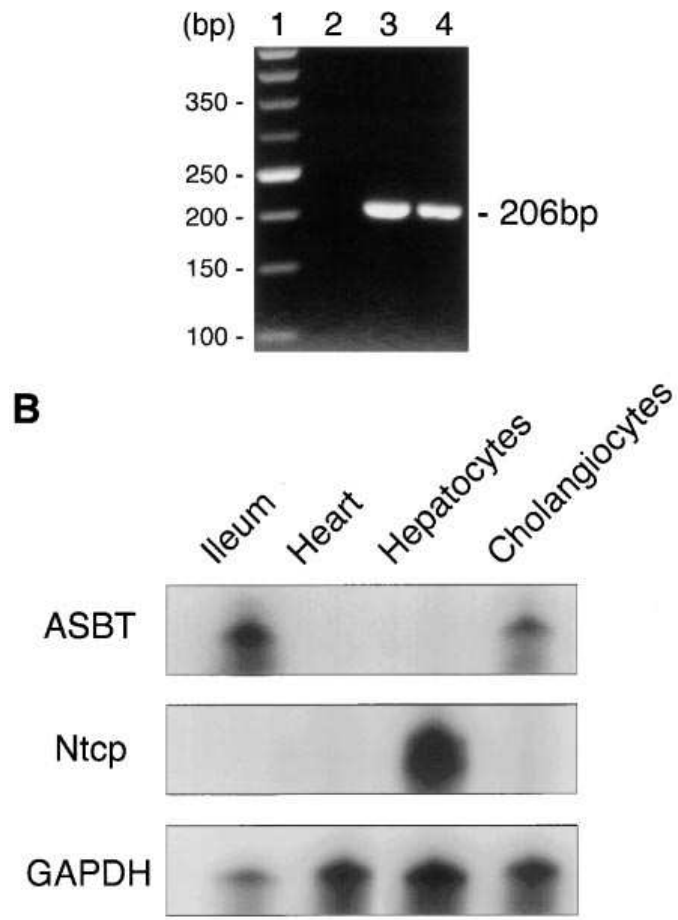

Figure 3. (A) RT-PCR using degenerate primers for Ntcp and ASBT. Agarose gel (2\%) electrophoresis of RT-PCR products using degenerate primers for Ntcp and ASBT. Lane 1, molecular weight markers; lane 2, negative control; lane 3, total RNA from isolated rat hepatocytes; lane 4, total RNA from NRC. For each reaction, $1 \mu \mathrm{g}$ of total RNA was used as template. $(B)$ RPAs for ASBT, Ntcp, and GAPDH. Total RNA $(10 \mu \mathrm{g})$ was used from each tissue or cell type. GAPDH was used as a housekeeping gene. 

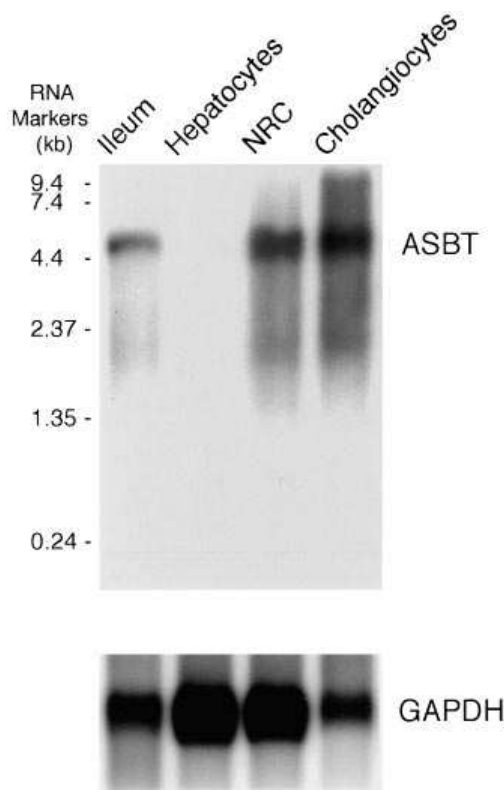

Figure 4. Northern blot analysis for ASBT. Poly $(\mathrm{A})^{+}$RNA $(2 \mu \mathrm{g}$ of each sample) was isolated from terminal ileum, freshly isolated hepatocytes, NRC, and freshly isolated cholangiocytes, and was hybridized with our ASBT probe. GAPDH was used as a housekeeping gene.

ing to the ASBT was present in brush border membranes derived from rat ileum, and absent from crude hepatocyte plasma membranes. A protein of identical molecular mass was also seen in crude NRC plasma membranes. When NRC crude plasma membranes were further fractionated into apical and basolateral domains, the $48-\mathrm{kD}$ protein was present in the apical but not basolateral membranes. In addition, a band of $92 \mathrm{kD}$ was also present in ileum, crude, and apical cholangiocyte plasma membrane but was absent in hepatocytes and basolateral plasma membranes (Fig. $6 A$ ). This $92-\mathrm{kD}$ protein appears to be a dimer of the ASBT, as it has been reported previously in brush border membranes from ileum (5) and kidney (26). The specificity of the anti-ASBT antibody is demonstrated in Fig. $6 \mathrm{~B}$. This illustration shows that both the 48- and 92-kD bands of ASBT were blocked completely when the anti-ASBT antibody was preabsorbed with the 14-amino acid peptide. The nonspecific bands after preabsorption with the peptide are noted in Fig. $6 \mathrm{~B}$ (arrowheads). Densitometric analysis of the ASBT protein (both 48- and 92-kD) from the immunoblot revealed that the ileal brush border membranes contained approximately sevenfold the amount of ASBT protein compared with apical cholangiocyte plasma membrane derived from NRC. To verify the localization of the ASBT gene product in normal rat liver, indirect immunohistochemistry was per-

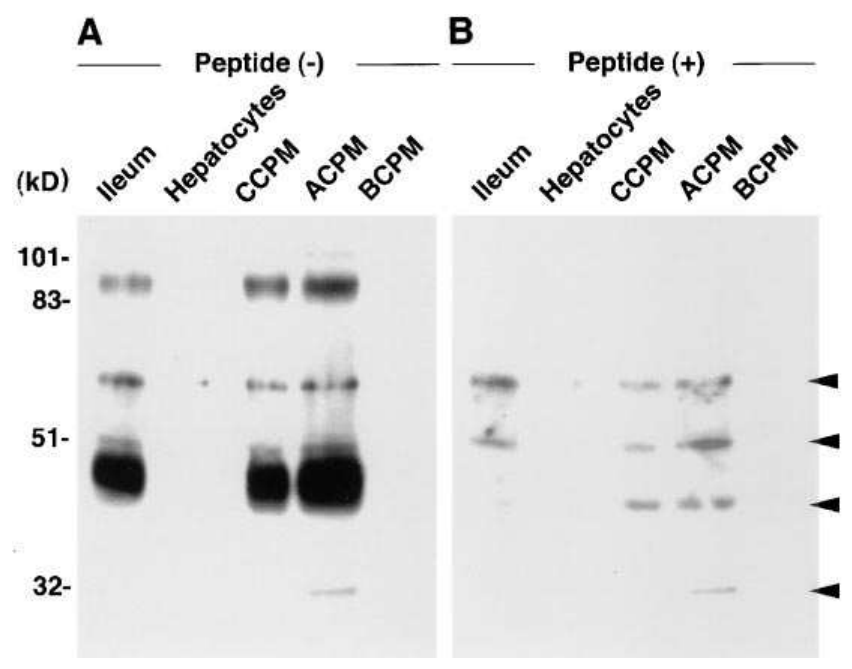

Figure 6. Expression of ASBT protein in plasma membranes obtained from NRC. Ileal brush border membranes $(5 \mu \mathrm{g})$, hepatocyte crude plasma membranes $(70 \mu \mathrm{g})$, cholangiocyte crude $(70 \mu \mathrm{g})$, apical $(70 \mu \mathrm{g})$ and basolateral $(70 \mu \mathrm{g})$ plasma membranes derived from NRC (CCPM, $A C P M$, and $B C P M$, respectively) were subjected to SDS-PAGE on a $10 \%$ polyacrylamide gel. Immunoblotting was performed as described in Methods. (A) The 48- and 92-kD bands that represent the monomer and homodimer of the ASBT protein, respectively, were present in ileum, cholangiocyte crude, and apical plasma membranes, but absent from hepatocyte and basolateral plasma membranes. $(B)$ Preabsorption of the anti-ASBT antibody with the 14-amino acid peptide prevented the expression of both the 48- and 92-kD bands of ASBT protein. Arrowheads, Nonspecific bands.

formed using the same specific antibody as in Western blot. Fig. 7 shows that the apical domain of cholangiocytes is decorated with the antibody (Fig. $7 \mathrm{D}$ ), whereas no staining was observed in the negative control (Fig. 7 C). The apical localization of the ASBT protein in normal rat bile ducts in liver concurs with its apical localization in rat terminal ileum (Fig. 7 B).

\section{Discussion}

The work described here tests directly the hypothesis that biliary epithelia can transport conjugated bile acids. Our data demonstrate that $(a)$ transcellular transport of taurocholate in cultured cholangiocytes is $\mathrm{Na}^{+}$dependent and unidirectional (i.e., apical to basolateral but not basolateral to apical); (b)

\section{CK-19}

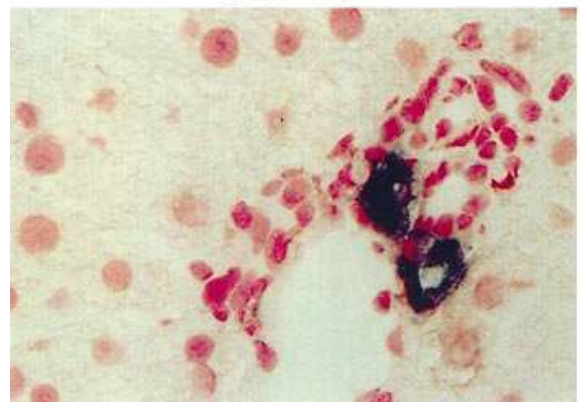

\section{ASBT}

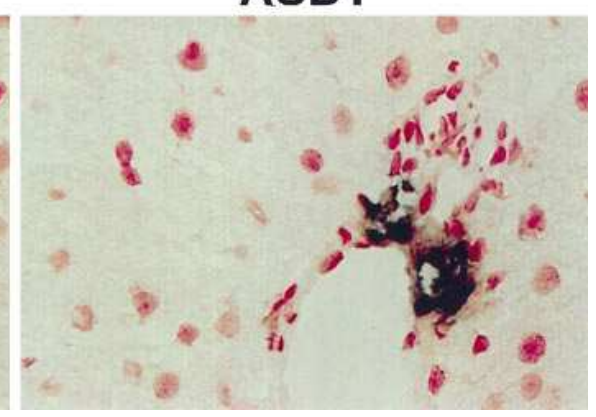

Figure 5. In situ RT-PCR on normal rat liver using primers for CK-19 and ASBT. Serial sections of normal rat liver amplified with specific primers for CK-19, a specific marker of biliary epithelia, and ASBT (original magnification $\times 400$ ). 
A
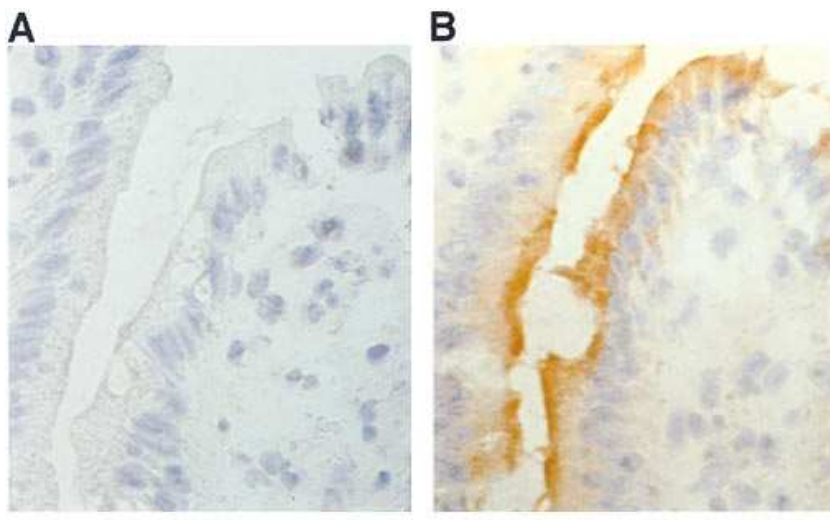

C
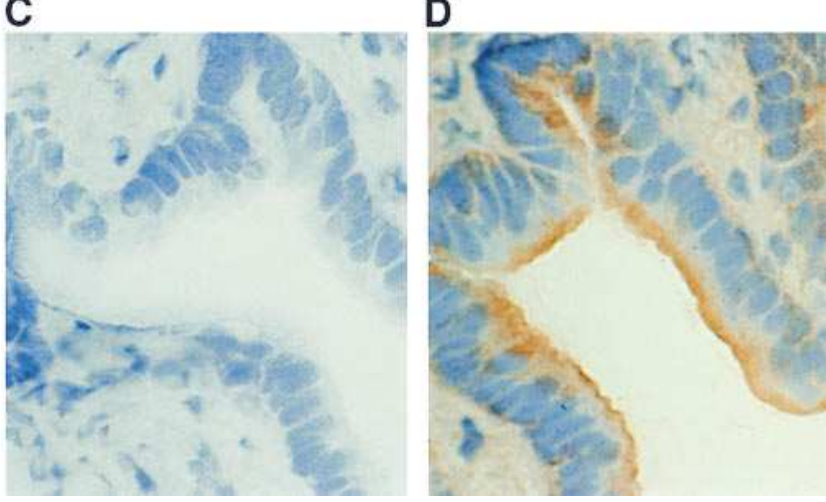

Figure 7. Indirect immunohistochemistry of ASBT in normal rat terminal ileum and liver. $(A)$ Ileum negative control (no primary antibody was used, and no staining is observed) (original magnification $\times 400)$. (B) Ileum incubated with the primary anti-ASBT peptide antibody. The apical domain of enterocytes is decorated (original magnification $\times 400$ ). $(C)$ Bile duct negative control (no primary antibody was used, and no staining is demonstrated) (original magnification $\times 400)$. (D) Bile duct incubated with the primary anti-ASBT peptide antibody. The apical domain of cholangiocytes is labeled (original magnification $\times 400$ ).

taurocholate uptake in apical cholangiocyte vesicles follows Michaelis-Menten kinetics, is saturable, and is $\mathrm{Na}^{+}$dependent; (c) message for ASBT is present in cultured and freshly isolated rat cholangiocytes and is expressed in cholangiocytes in vivo; and $(d)$ ASBT protein is localized in cholangiocytes at their apical plasma membrane domain. These data are consistent with the notion that cholangiocytes are involved functionally in the EHC of bile acids.

The EHC of bile acids involves the coordinated participation of both enterocytes and hepatocytes (2). The active absorption of bile acids by the distal ileum was described more than 30 years ago using everted rat intestinal sacs (27). Subsequently, using membrane vesicles derived from rat ileum, it was shown that bile acid transport involved an $\mathrm{Na}^{+}$-dependent process located selectively at the apical enterocyte domain (28, 29). Recently, the enterocyte protein responsible for ileal bile acid transport in the hamster was identified using COS cells in an expression cloning system (3). In that study, the authors cloned a molecule whose $\mathrm{Na}^{+}$dependence, saturability, substrate specificity (i.e., taurocholate), and tissue distribution (i.e., ileum) strongly suggested that it represented the presumed ileal $\mathrm{Na}^{+}$-dependent bile acid-transporting protein. Since then, the human and rat ASBT have also been cloned $(4,5)$. Interestingly, ASBT is also expressed in the apical domain of the renal tubules of the kidney (26). After ileal absorption of luminal bile acids via ASBT, bile acids enter the portal blood and are transported to the liver sinusoids, where hepatocytes efficiently extract them across their basolateral domain. This active uptake of bile acids by hepatocytes involves an Ntcp located on the sinusoidal (basolateral) hepatocyte membrane and accounts for the uptake of $>90 \%$ of conjugated cholates, and $75-80 \%$ of conjugated chenodeoxy-, deoxy-, and ursodeoxycholates by hepatocytes (6). In rat, Ntcp and ASBT share $37 \%$ amino acid identity (5).

Biliary epithelia (i.e., cholangiocytes) line the intrahepatic bile ducts and, as such, constitute an anatomical component of the EHC. Several recent observations are consistent with the possibility that cholangiocytes also participate functionally in the EHC of bile acids. First, cholangiocytes possess enzymes capable of conjugating and metabolizing bile acids (30). Second, recent experiments in rats have shown that bile acids stimulate the proliferative and secretory activities of cholangiocytes (31). Third, other investigators have described $\mathrm{Na}^{+}$-independent transport of conjugated fluorescent bile acids at the basolateral domain of cholangiocytes, using polarized intrahepatic bile duct units isolated from rat liver (32). Thus, while no transporters have been demonstrated directly on biliary epithelia, several lines of recent evidence, coupled with their anatomical location, are suggestive of the functional involvement of cholangiocytes in the EHC. This background, as well as the recent development of novel experimental models to study cholangiocyte biology, prompted us to address directly the interaction of bile acids with cholangiocytes.

Initially, we performed transport studies on confluent polarized monolayers of NRC, a model we had used previously to study the kinetics of glucose transport (21). These studies revealed $\mathrm{Na}^{+}$-dependent transcellular transport of taurocholate by NRC in a polar fashion (i.e., apical to basolateral but not basolateral to apical) (Fig. 1). This observation, coupled with evidence for $\mathrm{Na}^{+}$-independent transport of conjugated bile acids across the basolateral membrane of intrahepatic bile duct units (32), suggested the following tentative scenario: (a) cholangiocytes possess a functional $\mathrm{Na}^{+}$-dependent bile acid transporter at their apical domain that, given a favorable $\mathrm{Na}^{+}$ gradient, transports bile acids from the ductal lumen into the cholangiocyte; and $(b)$ the release of bile acids at the basolateral domain of NRC, as we observed here, may be accomplished by a basolateral $\mathrm{Na}^{+}$-independent transporter (32), assuming it is bidirectional. This scenario is consistent with our observation that $\mathrm{Na}^{+}$-dependent taurocholate transport in the apical to basolateral direction is fivefold greater than $\mathrm{Na}^{+}$independent taurocholate transport in the basolateral to apical direction (Fig. 1), at least in noncholestatic conditions.

We used well-characterized vesicles derived from the apical domain of NRC (17) to extend our initial observations and to examine further the kinetic parameters of this $\mathrm{Na}^{+}$-dependent transport process. We observed that taurocholate uptake by apical vesicles was linear in the initial $15 \mathrm{~s}$ of the uptake process (Fig. $2 A$ ) and saturable at $\sim 200 \mu \mathrm{M}$ (Fig. $2 B$ ), a value similar to the value for saturation of taurocholate uptake noted by others in Caco-2 monolayers (15). Using this model, the apparent $K_{\mathrm{m}}$ and $V_{\max }$ values for taurocholate uptake at initial rates (i.e., $10 \mathrm{~s}$ ) were $209 \pm 45 \mu \mathrm{M}$ and $1.23 \pm 0.14 \mathrm{nmol} /$ $\mathrm{mg} / 10 \mathrm{~s}$, respectively. Comparison of our kinetic data to pub- 


\begin{tabular}{|c|c|c|c|}
\hline System & $K_{\mathrm{m}}$ & $V_{\max } *$ & Reference \\
\hline & $\mu M$ & & \\
\hline Apical vesicles (NRC) & $209 \pm 45$ & $1.23 \pm 0.14 \mathrm{nmol} / \mathrm{mg} / 10 \mathrm{~s}(7.38 \pm 0.84 \mathrm{nmol} / \mathrm{mg} / \mathrm{min})$ & This study \\
\hline BBMV (adult rat distal ileum) & 125 & $0.72 \mathrm{nmol} / \mathrm{mg} / 15 \mathrm{~s}(2.88 \mathrm{nmol} / \mathrm{mg} / \mathrm{min})$ & 28 \\
\hline BBMV (21 d, rat distal ileum) & $130.6 \pm 18.9$ & $10.15 \pm 0.44 \mathrm{nmol} / \mathrm{mg} / \mathrm{min}$ & 22 \\
\hline BBMV (adult rat distal ileum) & $70.1 \pm 12.6$ & $13.42 \pm 0.59 \mathrm{nmol} / \mathrm{mg} / \mathrm{min}$ & 22 \\
\hline BBMV (21 d, rat distal ileum) & $79 \pm 29$ & $194 \pm 25 \mathrm{pmol} / \mathrm{mg} / 10 \mathrm{~s}(1.16 \pm 0.15 \mathrm{nmol} / \mathrm{mg} / \mathrm{min})$ & 26 \\
\hline BBMV (21 d, rat kidney) & $70 \pm 25$ & $113 \pm 19 \mathrm{pmol} / \mathrm{mg} / 10 \mathrm{~s}(0.67 \pm 0.11 \mathrm{nmol} / \mathrm{mg} / \mathrm{min})$ & 26 \\
\hline
\end{tabular}

$* V_{\max }$ data are provided as reported, and extrapolated to 1 min (in parentheses) to allow ready comparison.

lished studies for bile acid transport in BBMV derived from distal ileum $(22,28,26)$ and kidney $(26)$ is shown in Table I. Overall, the kinetic parameters of taurocholate transport by cholangiocyte apical vesicles are comparable to published data using BBMV from distal ileum $(22,28)$.

Having shown that NRC are able to transport taurocholate at their apical domain by a saturable $\mathrm{Na}^{+}$-dependent process with kinetic parameters comparable to published data for ASBT, we initiated experiments to identify unequivocally the putative bile acid transporter that could account for this uptake. To do this, we used a variety of molecular techniques which revealed that both cultured and freshly isolated cholangiocytes possess the same message for ASBT as the terminal ileum (Fig. $3 B$ and Fig. 4) but not for Ntcp (Fig. 3 B). Using in situ RT-PCR, we showed that cholangiocytes also express the ASBT message in vivo (Fig. 5). Our final goal was to determine the domain distribution of ASBT in cholangiocytes. Using immunoblot analysis and a separation scheme for cholangiocyte plasma membranes developed by us (17), we demonstrated that ASBT protein is present in the apical but not basolateral plasma membrane domain of cholangiocytes (Fig. $6 \mathrm{~A}$ ). Finally, indirect immunohistochemistry in normal rat liver showed apical localization of the ASBT gene product in cholangiocytes (Fig. $7 \mathrm{D}$ ). Previous work in the isolated perfused rat liver provided evidence for passive luminal uptake of unconjugated bile acids by biliary epithelia (10). Studies in intact rats using retrograde intrabiliary injection of radiolabeled bile acids showed absorption of both unconjugated and, to a lesser degree, conjugated bile acids by biliary epithelia (33). Our data in cellular and subcellular systems extend these whole-organ and intact animal studies and provide the first direct evidence that cholangiocytes actively transport conjugated bile acids at their apical domain via ASBT. Concurrently, Alpini et al. also identified the expression of ASBT in large cholangiocytes from normal rat liver (34).

The physiologic relevance of the presence of this transporter in biliary epithelia remains unclear. We suggest that ASBT in cholangiocytes may serve several different but possibly interrelated physiologic functions. First, its presence may help to regulate bile formation by both hepatocytes and cholangiocytes. For example, it may provide a cholehepatic shunt pathway for conjugated bile acids (analogous to that proposed by Hofmann for unconjugated bile acids [10]). Also, it might promote water absorption in specific segments of the biliary tree, since bile acid uptake from the ductal lumen would create inward (absorptive) osmotic gradients. Relevant to this possibility is our previous observation that biliary epithelia (but not hepatocytes) (35) express the transmembrane water channel, aquaporin-1 (36), a protein that permits the rapid movement of water in response to small osmotic gradients. A second possible physiologic role for bile acid uptake in ASBT by cholangiocytes is to affect cholangiocyte signaling pathways, including protein kinase $\mathrm{C}, \mathrm{Mg}^{2+}$, and cAMP. Bile acids are known to activate protein kinase $\mathrm{C}$ in hepatocytes (37) and enterocytes (38), and to increase cytosolic free $\mathrm{Mg}^{2+}$ in hepatocytes (39). More recently, exposure of isolated cholangiocytes to bile acids has been reported to induce cell proliferation and to increase secretin receptor gene expression and secretin-induced cAMP response (31). An additional theoretical role for this carrier protein in biliary epithelia is the transport of xenobiotics into cholangiocytes, leading either to their recycling to hepatocytes via a cholehepatic shunt pathway and/or to their further metabolism by biliary epithelia. Given the high substrate specificity of ASBT for bile acids demonstrated in other systems (3), this possibility may be unlikely.

\section{Acknowledgments}

The authors would like to thank Dr. G.J. Gores for critical review of the manuscript, Dr. B.L. Shneider for helpful advice, and Ms. Dawn Lubinski for excellent secretarial assistance.

This work was supported by grants DK-24031 and DK-46577 from the National Institutes of Health, by the Mayo Foundation, by a fellowship from the Hartz Foundation (to Dr. K.N. Lazaridis), by an Astra-Merck Advanced Research Training Award (to Dr. K.N. Lazaridis) from the American Digestive Health Foundation and the American Gastroenterological Association, and by the Evelyn and James Silver Postdoctoral Research Fellow Award (to Dr. K.N. Lazaridis) from the American Liver Foundation.

\section{References}

1. Vlahcevic, Z.R., D.M. Heuman, and P.B. Hylemon. 1996. Physiology and pathophysiology of enterohepatic circulation of bile acids. In Hepatology: A Textbook of Liver Disease, Volume 1. 3rd ed. D. Zakim and T.D. Boyer, editors. W.B. Saunders Co., Philadelphia. 376-417.

2. Dawson, P.A., and P. Oelkers. 1995. Bile acid transporters. Curr. Opin. Lipidol. 6:109-114.

3. Wong, M.H., P. Oelkers, A.L. Craddock, and P.A. Dawson. 1994. Expression cloning and characterization of the hamster ileal sodium-dependent bile acid transporter. J. Biol. Chem. 269:1340-1347.

4. Wong, M., P. Oelkers, and P.A. Dawson. 1995. Identification of a mutation in the ileal sodium-dependent bile acid transporter gene that abolishes transport activity. J. Biol. Chem. 270:27228-27234.

5. Shneider, B.L., P.A. Dawson, D.-M. Christie, W. Hardikar, M. Wong, and F.J. Suchy. 1995. Cloning and molecular characterization of the ontogeny of the rat ileal sodium-dependent bile acid transporter. J. Clin. Invest. 95:745-754.

6. Meier, P.J. 1995. Molecular mechanisms of hepatic bile salt transport from sinusoidal blood into bile. Am. J. Physiol. 269:G801-G812. 
7. Hagenbuch, B., B. Stieger, M. Foguet, H. Lubbert, and P.M. Meier. 1991. Functional expression cloning and characterization of the hepatocyte $\mathrm{Na}^{+} / \mathrm{bile}$ acid cotransport system. Proc. Natl. Acad. Sci. USA. 88:10629-10633.

8. Hagenbuch, B., and P.J. Meier. 1996. Sinusoidal (basolateral) bile salt uptake systems of hepatocytes. Semin. Liver Dis. 16:129-136.

9. Jacquemin, E., B. Hagenbuch, B. Stieger, A. Wolkoff, and P. Meier. 1994. Expression cloning of a rat liver $\mathrm{Na}^{+}$-independent organic anion transporter. Proc. Natl. Acad. Sci. USA. 91:133-137.

10. Yoon, Y.B., L.R. Hagey, A.F. Hofmann, D. Gurantz, E.L. Michelotti, and J.H. Steinbach. 1986. Effect of side-chain shortening on the physiologic properties of bile acids: hepatic transport and effect on biliary secretion of 23nor-ursodeoxycholate in rodents. Gastroenterology. 90:837-852

11. Gurantz, D., C.D. Schteingart, L.R. Hagey, J.H. Steinbach, T. Grotmol, and A.F. Hofmann. 1991. Hypercholeresis induced by unconjugated bile acid infusion correlates with recovery in bile of unconjugated bile acids. Hepatology. 13:540-550.

12. Roberts, S.K., S.M. Kuntz, G.J. Gores, and N.F. LaRusso. 1993. Regulation of bicarbonate-dependent ductular bile secretion assessed by lumenal micropuncture of isolated intrahepatic bile ducts. Proc. Natl. Acad. Sci. USA. 90: 9080-9084.

13. Tietz, P.S., R.T. Holman, L.J. Miller, and N.F. LaRusso. 1995. Isolation and characterization of rat cholangiocyte vesicles enriched in apical or basolateral plasma membrane domains. Biochemistry. 34:15436-15443.

14. Vroman, B., and N.F. LaRusso. 1996. Development and characterization of polarized primary cultures of rat intrahepatic bile duct epithelial cells. Lab. Invest. 74:303-313.

15. Chandler, C.E., L.M. Zaccaro, and J.B. Moberly. 1993. Transepithelial transport of cholyltaurine by Caco-2 cell monolayers is sodium dependent. Am. J. Physiol. 264:G1118-G1125.

16. Duffy, M.C., B.L. Blitzer, and J.L. Boyer. 1983. Direct determination of the driving forces for taurocholate uptake into rat liver plasma membrane vesicles. J. Clin. Invest. 72:1470-1481.

17. Tietz, P., S. Levine, R. Holman, C. Fretham, and N.F. LaRusso. 1997. Characterization of apical and basolateral plasma membrane domains derived from cultured rat cholangiocytes. Anal. Biochem. In press.

18. Alpini, G., J.O. Phillips, B. Vroman, and N.F. LaRusso. 1994. Recent advances in the isolation of liver cells. Hepatology. 20:494-514.

19. Chomczynsky, P., and N. Sacchi. 1987. Single-step method of RNA isolation by acid guanidium thiocyanate-phenol-chloroform extraction. Anal. Biochem. 162:156-159.

20. Patel, V.G., A. Shum-Siu, B.W. Heniford, T.J. Wieman, and F.J. Hendler. 1994. Detection of epidermal growth factor receptor mRNA in tissue sections from biopsy specimens using the in situ polymerase chain reaction. Am. J. Pathol. 144:7-14.

21. Lazaridis, K.N., L. Pham, B. Vroman, P. de Groen, and N.F. LaRusso. 1997. Kinetic and molecular identification of sodium-dependent glucose transporter in normal rat cholangiocytes. Am. J. Physiol. 272:G1168-G1174.

22. Moyer, M.S., J.E. Heubi, A.L. Goodrich, W.F. Balistreri, and F.J. Suchy. 1986. Ontogeny of bile acid transport in brush border membrane vesicles from rat ileum. Gastroenterology. 90:1188-1196.

23. Towbin, H., T. Staehelin, and J. Gordon. 1979. Electrophoretic transfer of proteins from polyacrylamide gels to intracellular sheets: procedure and some applications. Proc. Natl. Acad. Sci. USA. 76:4350-4354.

24. LeSage, G., S. Glaser, S. Gubba, W.E. Robertson, J.L. Phinizy, J. Lasater, R.E.D. Rodgers, and G. Alpini. 1996. Regrowth of a rat biliary tree after $70 \%$ partial hepatectomy is coupled to increased secretin-induced ductal secretion. Gastroenterology. 111:1633-1644.

25. Liang, D., B. Hagenbuch, B. Stieger, and P.J. Meier. 1993. Parallel decrease of $\mathrm{Na}^{+}$-taurocholate contransport and its encoding mRNA in primary culture of rat hepatocytes. Hepatology. 18:1162-1166.

26. Christie, D.M., P.A. Dawson, S. Thevananther, and B.L. Shneider. 1996 Comparative analysis of the ontogeny of a sodium-dependent bile acid transporter in rat kidney and ileum. Am. J. Physiol. 271:G377-G385.

27. Lack, L., and I.M. Weiner. 1961. In vitro absorption of bile salts by small intestine of rats and guinea pigs. Am. J. Physiol. 200:313-317.

28. Wilson, F.A., and L.L. Treanor. 1979. Glycodeoxycholate transport in brush border membrane vesicles isolated from rat jejunum and ileum. Biochim. Biophys. Acta. 554:430-440.

29. Wilson, F.A. 1981. Intestinal transport of bile acids. Am. J. Physiol. 241: G83-G92.

30. Hylemon, P.B., P.M. Bohdan, A.E. Sirica, D.M. Heuman, and Z.R. Vlahcevic. 1990. Cholesterol and bile acid metabolism in cultures of primary rat bile ductular epithelial cells. Hepatology. 11:982-988.

31. Alpini, G., S.S. Glaser, W.E. Robertson, J. Phinizy, R. Rodgers, A. Caliguiri, and G. LeSage. 1997. Bile acids stimulate proliferative and secretory events in large but not small cholangiocytes. Am. J. Physiol. 273:G518-G529.

32. Benedetti, A., A. Di Sario, L. Marucci, G.S. Baroni, C.D. Schteingart, H.-T. Ton-Nu, and A.F. Hofmann. 1997. Carrier-mediated transport of conjugated bile acids across the basolateral membrane of biliary epithelial cells. Am. J. Physiol. 272:G1416-G1424.

33. Farges, O., M. Corbic, M. Dumont, M. Maurice, and S. Erlinger. 1989. Permeability of the rat biliary tree to ursodeoxycholic acid. Am. J. Physiol. 256: G653-G660.

34. Alpini, G., S.S. Glaser, W.E. Robertson, J. Phinizy, R.E. Rodgers, and G.D. LeSage. 1996. Genetic and functional expression of the ileal $\mathrm{Na}^{+}$-dependent bile acid transporter and $14 \mathrm{kD}$ cytosolic bile acid binding protein in large but not small cholangiocytes from normal rat liver. Hepatology. 24:255A. (Abstr.)

35. Yano, M., R. Marinelli, S.K. Roberts, V. Balan, L. Pham, J.E. Tarara, P.C. de Groen, and N.F. LaRusso. 1996. Rat hepatocytes transport water mainly via a non-channel-mediated pathway. J. Biol. Chem. 271:6702-6707.

36. Roberts, S.K., M. Yano, Y. Ueno, L. Pham, G. Alpini, P. Agre, and N.F. LaRusso. 1994. Cholangiocytes express the aquaporin CHIP and transport water via a channel-mediated mechanism. Proc. Natl. Acad. Sci. USA. 91:1300913013.

37. Stravitz, R.T., Y.-P. Rao, Z.R. Vlahcevic, E.C. Gurley, W.D. Jarvis, and P.B. Hylemon. 1996. Hepatocellular protein kinase $\mathrm{C}$ activation by bile acids: implications for regulation of cholesterol $7 \alpha$-hydroxylase. Am. J. Physiol. 271: G293-G303.

38. Pongracz, J., P. Clark, J.P. Neoptolemos, and J.M. Lord. 1995. Expression of protein kinase $\mathrm{C}$ isoenzymes in colorectal cancer tissue and their differential activation by different bile acids. Int. J. Cancer. 61:35-39.

39. Patel, T., S.F. Bronk, and G.J. Gores. 1994. Increases of intracellular magnesium promote glycodeoxycholate-induced apoptosis in rat hepatocytes. J. Clin. Invest. 94:2183-2192. 